Revista Eletrônica Gestão \& Saúde ISSN: 1982 - 4785

Barbosa KR, Reis AS, Leitão FO e Gomes VC.

Artigo Original

\title{
Gestão da qualidade hospitalar: estudo de caso sobre a prevenção de falhas em um hospital público
}

Hospital Quality Management: case study on the prevention of failures in a public hospital Gestión de calidad hospitalaria: estudio de caso sobre la prevención de fallos en un hospital público

Karine Rangel Barbosa ${ }^{1}$ Silvia Araújo dos Reis ${ }^{2}$ Fabrício Oliveira Leitão $^{3}$ Vanessa Cabral Gomes ${ }^{4}$

\section{Resumo}

Segundo decisão da Diretoria Colegiada da Agência Nacional de Vigilância Sanitária, todos os serviços de saúde do Brasil devem ter um Núcleo de Segurança do Paciente (NSP). Cada NSP deve elaborar um Plano de Segurança do Paciente em Serviços de Saúde

${ }^{1}$ Bacharela Em Administração De Empresas. E-Mail: Karinerangelb@Gmail.Com.

${ }^{2}$ Doutorado E Mestrado Em Engenharia De Produção. Universidade De Brasilia (Unb). Docente Do Departamento De Administração - FACE. E-Mail: Silviareis@Unb.Br.

${ }^{3}$ Possui graduação em administração, especialização em Gestão Educacional, mestrado em Agronegócios, e doutorado em Transportes. Atualmente é professor adjunto do departamento de Administração da Universidade de Brasília, e da pós-graduação em Agronegócios, trabalhando nas linhas de pesquisa voltadas para a área da Gestão da Produção e Operações e Logística. É membro dos grupos de pesquisa GECOMP/UnB (Grupo de Estudos sobre a Sustentabilidade e Competitividade do Agronegócio/UnB) onde lidera uma linha de pesquisa sobre Logística no Agronegócio; GEALOGS (Grupo de Estudos e Pesquisa Avançados em Logística e Supply Chain Management); e GOMETA (Grupo de Pesquisa em Operações, Logística e Métodos de Apoio à Decisão). http://lattes.cnpq.br/7050062167480297

${ }^{4}$ Professora Adjunta do Departamento de Administração da Universidade de Brasília. Possui graduação em Economia pela Universidade de Brasília (2008), mestrado em Administração (2012) e doutorado em Administração (2016) pela mesma instituição. Atualmente também é professora doutora da Faculdade Presbiteriana Mackenzie. Com a formação diversificada, atua nas mais diversas áreas de conhecimento: Economia, Gestão de Ciência, Tecnologia e Inovação, Logística Empresarial, Administração da Produção, Matemática Aplicada à Administração, Estatística Aplicada, Matemática Financeira.

Vanessa Cabral Gomes -nessa.unb@gmail.com.
(PSP) na área de cirurgia segura. Esta pesquisa objetivou analisar meios para a redução de falhas cirúrgicas em um hospital público com base em seu PSP. Para tanto, buscou-se analisar o estado atual da meta; identificar as causas da baixa adesão ao checklist e do seu mau preenchimento se for o caso; e montar um plano de ação. Trata-se de um estudo de caso descritivo, de natureza quali-quantitativa. Foram utilizados como instrumentos de coleta de dados entrevistas, análise documental e observação direta. Os resultados indicaram que a adesão e a qualidade do preenchimento dos checklists não estão satisfatórias e que as principais causas disso são: falta de treinamentos, baixa conscientização em relação à cirurgia segura, desmotivação dos profissionais, baixa participação dos gestores e comunicação deficitária entre a equipe. Por fim, montou-se um plano de ação com base nas ferramentas da gestão da qualidade e no ciclo PDCA.

Descritores: Segurança do paciente. Cirurgia segura. Gestão da qualidade em saúde. Checklist cirúrgico.

\section{Abstract}


According to a decision of the Collegiate Board of the Agência Nacional de Vigilância Sanitária, all health services in Brazil must have a Patient Safety Center (PSC). Each PSC should develop a Health Care Patient Safety Plan (PSP) in the safe surgery's area. This research aimed to analyze means for the reduction of surgical failures in a public hospital based on its PSP. To do so, it was sought to analyze the current state of the goal; identify the causes of low adherence to the checklist and its unsatisfactory completion, if applicable; and put together a plan of action. The research is a descriptive case study of quantitative and qualitative nature. Interviews, documentary analysis and direct observation were used as instruments of data collection. The results indicated that adherence and quality of the checklists are not satisfactory and that the main causes of this are: lack of training, low awareness of safe surgery, lack of motivation of the professionals, low participation of managers and lack of communication between the team. Finally, an action plan was set up based on quality management and the PDCA cycle.

Keywords: Patient safety. Safe surgery. Health Quality management. Surgical checklist.

\section{Resumen}

Según una decisión de la Junta Colegiada de la Agencia Nacional de Vigilancia Sanitaria, todos los servicios de salud en Brasil deben tener un Centro de Seguridad del Paciente
(NSP). Cada NSP debe desarrollar un Plan de seguridad del paciente (PSP) en el área de la cirugía segura. Esta investigación tuvo como objetivo analizar los medios para reducir las fallas quirúrgicas en un hospital público, según su PSP. Para ello, se buscó analizar el estado actual de la meta; identificar las causas de la baja adherencia a la lista de verificación y su deficiente finalización, si corresponde; y armar un plan de acción. La investigación se clasifica como un estudio de caso descriptivo de carácter cuantitativo y cualitativo. Se utilizaron como instrumentos de recopilación de datos entrevistas, análisis documental y observación directa. Los resultados indicaron que la adherencia y la calidad de las listas de verificación no son satisfactorias y que las principales causas de esto son: falta de capacitación, poca conciencia de la cirugía segura, falta de motivación de los profesionales, baja participación de los gerentes y falta de comunicación entre el equipo. Finalmente, se estableció un plan de acción basado en herramientas de gestión de calidad y el ciclo PDCA.

Descriptores: Seguridad del paciente. Cirugía segura. Gestión de la calidad en salud. Lista de comprobación quirúrgica.

\section{Introdução}

Organização Mundial da Saúde (OMS) criou a Aliança Mundial para a Segurança do Paciente, com objetivo de impulsionar esforços globais para o fortalecimento da segurança do paciente em todos os seus países 
membros. Seis metas mundiais foram estabelecidas, quais sejam: identificação correta do paciente, comunicação efetiva, segurança do processo medicamentoso, cirurgia segura, redução do risco de infecções associadas aos cuidados de saúde e prevenção de quedas ${ }^{(1)}$.

No Brasil, a Diretoria Colegiada da Agência Nacional de Vigilância Sanitária, por meio da Resolução da Diretoria Colegiada (RDC) de número 36, de 25 de julho de 2013, determinou a criação de um Núcleo de Segurança do Paciente (NSP) por parte da direção de todos os serviços de saúde do país. Uma das funções de cada NSP é a de elaborar um Plano de Segurança do Paciente em Serviços de Saúde (PSP) específico para a unidade na qual ele funciona, o qual deve conter estratégias e ações de gestão de risco para as seis metas mundiais supracitadas ${ }^{(2) .}$

O hospital estudado criou o seu próprio NSP, o qual formulou os devidos PSPs. Este trabalho objetivou estudar um desses PSPs para análise e acompanhamento, qual seja: cirurgia segura. A meta estabelecida no PSP para tal área é: aumentar a segurança na realização de procedimentos cirúrgicos. Em face do contexto e dos problemas apresentados, o objetivo geral desta pesquisa é analisar meios para a redução de falhas cirúrgicas em um hospital público.

Com a finalidade de auxiliar no alcance do objetivo geral proposto, foram utilizadas ferramentas da gestão qualidade e a primeira etapa do ciclo PDCA nas seguintes etapas: analisar o estado atual da meta por meio de análise dos checklists cirúrgicos e observação direta; identificar as causas da baixa adesão ao checklist e do seu mau preenchimento, caso a análise supracitada demonstre tal necessidade; e montar um plano de ação.

Diante do contexto apresentado, é importante frisar que o presente estudo supre uma lacuna no meio científico, pois não foram encontrados estudos relacionados ao alcance de metas em hospitais públicos.

\section{Revisão da Literatura}

A gestão qualidade em saúde é uma estratégia administrativa para otimizar processos, aumentar a segurança do cuidado e potencializar os resultados de uma organização ${ }^{(3)}$. Para garantir que ela seja colocada em prática, necessita-se de recursos materiais apropriados, quantidade suficiente e capaz de recursos humanos, planejamento, controle, inspeção e apreciação das atividades realizadas ${ }^{(4)}$.

Em 2011, o Institute of Medicine (IOM) dos Estados Unidos publicou um relatório chamado "Cruzando o Abismo da Qualidade”. Em tal relatório, definiram-se seis dimensões para um sistema de saúde de qualidade, quais sejam: segurança do paciente, centralidade no paciente, eficácia, eficiência, oportunidade e equipe. É interessante frisar que segurança foi apresentada como uma das seis dimensões, 
dessa forma, entende-se que ela é um subconjunto da qualidade ${ }^{(5)}$.

O movimento em prol da segurança do paciente ganhou notoriedade após a publicação de estudos que mostraram consequências relacionadas a eventos adversos no final da década de 1990. Um deles foi o relatório lançado pelo IOM chamado "Errar é humano: construindo um sistema de saúde mais seguro" (1). Segundo essa publicação, houve uma taxa de $3,7 \%$ de incidência de eventos adversos em hospitais de Nova York no ano de 1984. Somado a isso, um milhão de danos e quase 100 mil mortes ocorrem todos os anos nos EUA devido a eventos adversos ${ }^{(6)}$.

Após a repercussão do relatório da IOM, a Organização Mundial da Saúde (OMS) adotou uma série de medidas com o intuito de transformar tal cenário. Uma delas foi a criação da Aliança Mundial para a Segurança do Paciente, que é, basicamente, a união de chefes de agências, formuladores de políticas públicas e grupos de pacientes, cujo objetivo é o de impulsionar esforços globais para o fortalecimento da segurança da assistência à saúde em todos os países membros da OMS. Sendo assim, foram estabelecidas 6 metas mundiais: identificação correta do paciente, comunicação efetiva, segurança do processo medicamentoso, cirurgia segura, redução do risco de infecções associadas aos cuidados de saúde e prevenção de quedas ${ }^{(1)}$.

No Brasil, o Ministério da Saúde criou o Programa Nacional de Segurança do Paciente
(PNSP) por meio da Portaria $n^{\circ} 529$ de $1^{\circ}$ de abril de 2013. O PNSP tem o objetivo geral de colaborar para a qualificação do cuidado em todas as instituições de saúde do Brasil. Dentre as estratégias do Programa, tem-se a confecção e auxílio na implementação de protocolos, guias e manuais de segurança do paciente, bem como a inserção de metas, de indicadores e de padrões de conformidade relativos à segurança do paciente ${ }^{(7)}$.

Somado a isso, a Diretoria Colegiada da Agência Nacional de Vigilância Sanitária, por meio da RDC n ${ }^{\circ} 36$, de 25 de julho de 2013, determinou a criação de um Núcleo de Segurança do Paciente (NSP) por parte da direção de todos os serviços de saúde do país (2). Dentre várias outras funções, cada NSP deve elaborar um Plano de Segurança do Paciente em Serviços de Saúde (PSP) para a instituição da qual ele faz parte. Em cada PSP, deve-se fixar, implementar e acompanhar estratégias e ações de gestão de risco em relação às seis metas mundiais, além de mais uma que foi estabelecida pelo governo brasileiro: redução de lesões por pressão ${ }^{(8)}$.

Em um estudo realizado em três hospitais de ensino do Rio de Janeiro, revelou-se que a incidência de pacientes que tiveram eventos adversos cirúrgicos foi de 3,5\% (38 de 1.103 pacientes), contudo, a proporção de casos evitáveis foi de $68,3 \%$ (28 de 41 eventos). É interessante destacar que mais de $60 \%$ dos casos foram classificados como pouco ou nada complexo e de baixo risco de ocorrer. 
Além disso, uma parte considerável dos eventos estava relacionada a não adesão à norma, ou seja, a falta de verificação ou de seguir o protocolo estabelecido $(31 \%)^{(9)}$.

Para evitar eventos adversos em cirurgias, especialistas da OMS prepararam um checklist cirúrgico composto por três fases, são elas: identificação (antes da indução anestésica), confirmação (antes da incisão cirúrgica, com a presença de todos os membros da equipe na sala de cirurgia) e registro (antes de o paciente sair da sala cirúrgica) ${ }^{(10)}$. Atitudes básicas como a checagem dos dados do paciente, informações clínicas da pessoa e do órgão, disponibilidade e bom funcionamento dos materiais e equipamentos podem impedir o início de uma série de complicações para o paciente ${ }^{(11)}$.

A lista de verificação de segurança cirúrgica, também chamada de checklist da cirurgia segura, é uma das estratégias adotadas pelo Plano Nacional de Segurança do Paciente. Além de ser considerada como um procedimento relativamente simples, ela representa uma promissora estratégia para a redução de danos relacionados a procedimentos cirúrgicos em todo o mundo. Contudo, sua implantação exige o engajamento e o esforço coletivo de todas as equipes da instituição e deve possuir o apoio fundamental dos gestores ${ }^{(1)}$.

\section{Métodos}

Em relação aos meios de investigação, optou-se por utilizar o estudo de caso. O estudo de caso é um método de investigação empírica que objetiva investigar um fenômeno contemporâneo de forma profunda e em seu contexto de mundo real ${ }^{(12)}$. Além disso, em relação aos fins, a presente pesquisa é descritiva. O principal objetivo das pesquisas descritivas é o de descrever as características de determinada população ou determinado fenômeno ${ }^{(13)}$.

Paralelamente, esta pesquisa é classificada como quantitativa e qualitativa, pois além de as informações serem quantificadas, classificadas e analisadas com o uso de recursos estatísticos, elas também foram utilizadas para interpretar fenômenos e para analisar os dados de maneira indutiva ${ }^{(14)}$.

O hospital estudado é classificado como público e geral, e está credenciado junto ao Ministério da Educação e Ministério da Saúde como hospital ensino. Nele são prestados serviços de atendimento emergencial e ambulatorial de média e alta complexidade. A área assistencial funciona 24 horas por dia e os setores administrativos das 8 h até às $18 \mathrm{~h}$. É interessante destacar que as cirurgias devem ser agendadas previamente com a devida autorização médica e após a realização de consultas ambulatoriais e exames de laboratório e imagem. Cada Unidade tem controle sobre os agendamentos.

Os instrumentos selecionados para o desenvolvimento desta pesquisa foram: três entrevistas, análise documental e observação direta. Em primeiro lugar, realizou-se uma entrevista não estruturada com a chefe do Núcleo de Segurança do Paciente do hospital 
Revista Eletrônica Gestão \& Saúde ISSN: 1982 - 4785 Barbosa KR; Reis AS; Leitão FO e Gomes VC.

estudado em maio de 2018. O objetivo foi o de entender o contexto da organização, bem como as questões relacionadas à temática da segurança do paciente. A duração foi de aproximadamente duas horas.

Em segundo lugar, fez-se uma pesquisa documental cujo objetivo foi o de analisar o estado atual da segurança do paciente cirúrgico no hospital estudado. A análise documental ficou restrita a dois grupos de documentos: checklists feitos e documentos gerais fornecidos pelos servidores do NSP. No primeiro grupo, foram analisados todos os 2.637 checklists feitos no período de janeiro de 2018 até setembro de 2018. A finalidade de tal análise foi a de quantificar os itens não preenchidos, ou seja, que ficaram em branco, o que auxiliou na análise da qualidade do preenchimento dos checklists. A coleta desses dados ocorreu por meio de uma média de 60 visitas à unidade hospitalar durante os meses de junho, agosto, setembro e outubro de 2018.

$\mathrm{O}$ segundo grupo refere-se aos documentos elaborados pelo próprio NSP, como o protocolo de cirurgia segura, o plano de segurança do paciente e indicadores de desempenho de anos anteriores. Além de protocolos e manuais sobre a temática de segurança do paciente produzidos por outros hospitais do Brasil. Todos os documentos do segundo grupo foram disponibilizados via email.

Em terceiro lugar, realizou-se uma observação direta: uma das pesquisadoras esteve presente em 8 cirurgias ao longo do
Gestão Da Qualidade Hospitalar: Estudo...

mês de outubro de 2018. A finalidade foi a de analisar como o checklists são preenchidos na prática para avaliar a qualidade do preenchimento e para sugerir possíveis pontos de melhorias. É interessante frisar que há um manual montado pela OMS sugerindo como a utilização da Lista de Verificação deve ser feita.

Em quarto e último lugar, realizou-se duas entrevistas semiestruturadas. A primeira entrevista foi realizada com a chefe do Núcleo de Segurança e com uma enfermeira do Centro Cirúrgico ao mesmo tempo. A segunda, por sua vez, foi realizada com a supervisora do Centro Cirúrgico. Ambas entrevistas duraram cerca de 1 hora cada uma. O objetivo da presente etapa foi o de entender o contexto de alguns itens do checklist, principalmente em relação aos graus de importância, possíveis causas de não preenchimento e sugestões de melhoria.

\section{Resultados}

Para que a meta de melhorar a segurança cirúrgica fosse alcançada, tomou-se como base o Ciclo PDCA, mais especificamente a primeira etapa dele, qual seja: "P" de planejar. Tal etapa é dividida em quatro partes: identificação do problema, análise do fenômeno, análise do processo e plano de ação ${ }^{(15)}$.

A identificação do problema, isto é, da meta de melhorar a segurança cirúrgica, aconteceu por meio da entrevista não estruturada com a chefe do Núcleo de 
Revista Eletrônica Gestão \& Saúde ISSN: 1982 - 4785 Barbosa KR; Reis AS; Leitão FO e Gomes VC.

Segurança, bem como pelos documentos fornecidos pelo setor e pelo estudo da bibliografia científica sobre o assunto. Em relação a análise do fenômeno, foram feitas as análises documentais e a observação direta. Além disso, estratificou-se o fenômeno tomando como base a sua quantidade de incidência (frequência).

Para a análise do processo, focou-se na busca pelas causas geradoras do problema. Nesse sentido, foram feitas duas entrevistas semiestruturadas, uma com a chefe e do Núcleo de Segurança e com uma enfermeira do Centro Cirúrgico, e a outra com a supervisora do Centro Cirúrgico. Por fim, elaborou-se um plano de ação, o qual foi dividido em vários planos de ação menores com o objetivo de facilitar a sua implementação.
Gestão Da Qualidade Hospitalar: Estudo...

Para alcançar a meta estabelecida, o Núcleo de Segurança do Paciente do hospital estudado dividiu-a em duas metas específicas, quais sejam: total adesão ao checklist da cirurgia segura e melhorar a qualidade de seu preenchimento. Sendo assim, ambas serão analisadas. A primeira etapa do Ciclo PDCA, planejamento, foi elaborada para as duas metas específicas de forma concomitante.

\section{Meta específica 1: Adesão total ao checklist}

O período de análise dos checklists correspondeu ao das cirurgias realizadas no período de $1^{\circ}$ de janeiro de 2018 até 30 de setembro de 2018. Nesse intervalo, foram realizadas 3.407 cirurgias e 2.637 checklists foram preenchidos, o que corresponde a uma média de $77 \%$ de adesão. Dessa forma, foi construído um histograma com a finalidade de representar a situação descrita (figura 1).

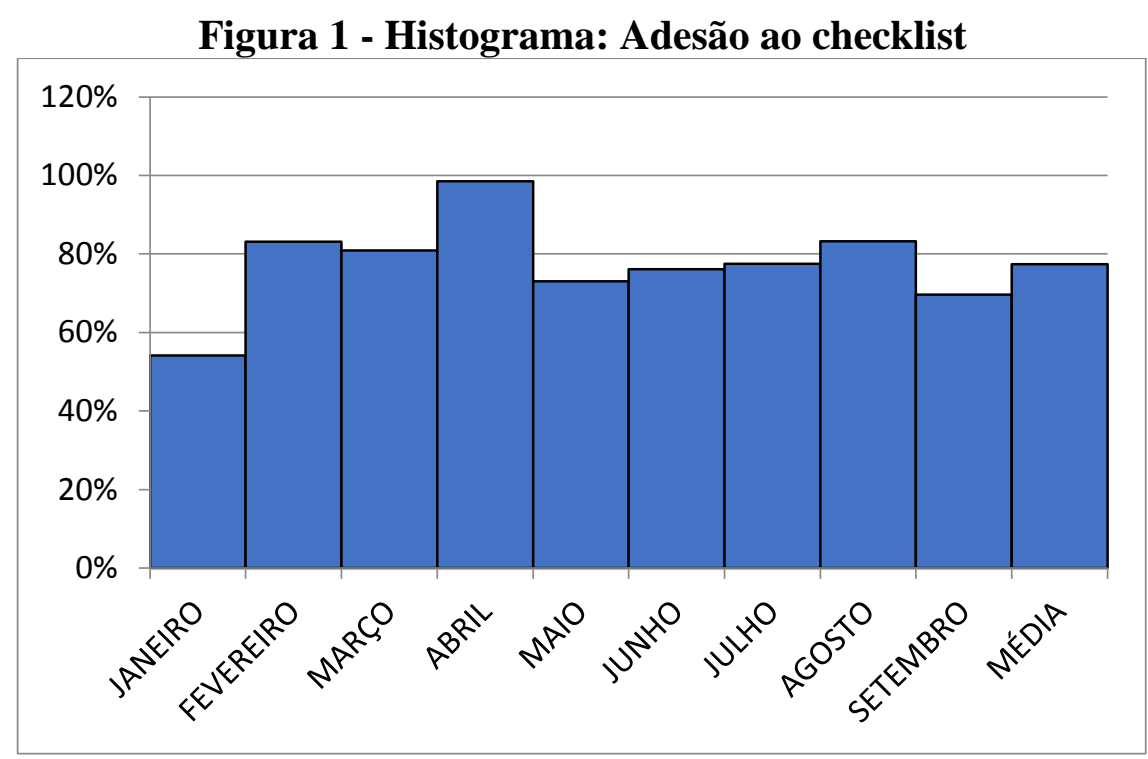

Fonte: elaborado pelos autores.

A meta estabelecida pelo NSP é de

total adesão. Nesse sentido, torna-se 
necessária uma intervenção. O primeiro passo é analisar as causas do não preenchimento, as quais foram apontadas pelas entrevistadas:

Uma das causas apontadas para a não adesão ao checklist da cirurgia segura está no fato de não existir um fluxo de atividades próprio do Centro Cirúrgico. Segundo uma das entrevistadas, "não se existe nada contínuo, não tem rotina, não tem fluxo de atendimento".

Também foi afirmado que não há conscientização em boa parte dos funcionários: "as pessoas não têm essa consciência, essa cultura". Uma delas defendeu que boa parte das pessoas não têm motivação para fazer o checklist porque não entendem a importância ou porque simplesmente não são cobradas. Ela concluiu que "ninguém vai querer acrescentar tarefas no seu trabalho diário se não vai haver cobrança".

Nesse contexto, afirmou-se que há poucos treinamentos sobre segurança do paciente cirúrgico. Além disso, que o pouco treinamento que é feito é perdido ao longo do tempo, porque não é passado para os novos funcionários do Centro Cirúrgico.

Outra dificuldade apontada é o fato de que há servidores que trabalham 20 horas e outros que trabalham 40 horas por semana. $\mathrm{Na}$ percepção de uma das entrevistadas, os que trabalham apenas 20 horas costumam ser menos envolvidos com as metas do hospital justamente pelo fato de não passarem mais tempo lá. Para ela, é importante ter visão de grupo, pois não há como implementar o uso do checklist sozinho, todos precisam estar envolvidos: "você só consegue o fruto do trabalho se você trabalhar junto. Para o trabalho no hospital, é necessário ter espírito de equipe".

Outra entrevistada afirmou que o checklist da cirurgia segura costuma ser mais preenchido nos hospitais particulares porque há mais cobrança e há punição, exemplos: suspensão, redução do salário e advertência escrita e verbal. Contudo, logo em seguida ela completou que mais importante do que punir, é criar o hábito, pois "no (hospital) privado, você faz porque você pode perder o seu emprego, não é essas mil maravilhas".

Em relação aos insumos, relatou-se a falta de materiais, problemas com a estrutura física e déficit de servidores. A supervisora do Centro Cirúrgico afirmou que "não temos os meios, não estou justificando, a segurança do paciente é uma coisa imprescindível, tem que ser feita, mas é muito difícil com o que a gente está vivendo agora: faltam insumos, falta de ar condicionado e isso é uma coisa que influencia negativamente". Além disso, outra entrevistada afirmou que muitos servidores querem prestar um serviço bem feito, mas que "o déficit de servidores faz com que eles não consigam prestar uma assistência de qualidade".

Foi dito que muitos circulantes, os quais são os responsáveis por coordenar o preenchimento dos checklists, podem se sentir intimidados em realizar o checklist, principalmente pela diferença do grau de instrução em relação aos cirurgiões e 
anestesistas. Nesse sentido, uma enfermeira afirmou que é necessário "descer ego $e$ qualificações que um se acha melhor que o outro e lembrar que cada um é importante, cada um tem o seu papel. A senhora que limpa o chão é tão importante quanto o cirurgião, porque se o chão estiver sujo, a cirurgia não vai acontecer. Todo mundo é importante".
Como todas as causas apontadas para a não adesão também foram apontadas para a baixa qualidade do preenchimento, optou-se, por questões didáticas, por apresentar os planos de ação apenas no próximo item. Ao seguir os planos de ação da meta específica 2, pretende-se alcançar a meta específica 1 de maneira concomitante. Para análise futura do alcance ou não da meta específica 1, é sugerido o seguinte indicador:

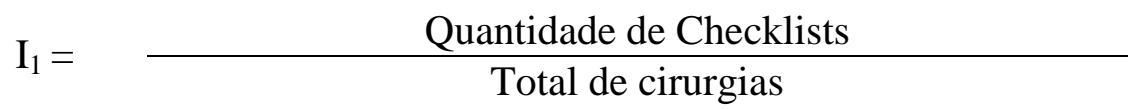

\section{Meta específica 2}

Por meio da meta específica 2, pretende-se melhorar a qualidade do preenchimento dos checklists. Com o objetivo de analisar o estado corrente de tal meta, todos os checklists preenchidos foram analisados detalhadamente e todos os itens que foram deixados em branco foram contabilizados. Somado a isso, oito cirurgias foram assistidas com a finalidade de verificar como eles estão sendo preenchidos na prática.

Para a priorização de análise dos itens, optou-se por utilizar a ferramenta da qualidade chamada de Diagrama de Pareto. O primeiro passo foi verificar os principais itens menos preenchidos. No caso deste trabalho, 20 itens representam os $80 \%$ do total de não preenchidos. Contudo, 4 foram selecionados para análise, os quais são os mais importantes dentro de cada bloco. O motivo de tal seleção se deu devido à repetitividade das causas do não preenchimento dos itens pertencentes aos mesmos blocos.

Os itens menos preenchidos e que foram escolhidos para análise são o Termo de Consentimento do Livre Esclarecido, com $81,30 \%$ de não preenchimento; marcação da lateralidade $(34,54 \%)$; presença de marcador $(25,46 \%)$; e contagem de instrumentais $(19,33 \%)$. É importante afirmar que, como sugerido pelo método PDCA, buscou-se entender o motivo de cada não preenchimento, bem como o seu contexto, suas causas e suas consequências. Tais informações foram obtidas nas entrevistas semiestruturadas e serviram de base para a criação de diagramas de causa e efeito. Ao final de cada item analisado, a pesquisadora sugeriu um plano de ação específico para ele.

Recomenda-se que a equipe cirúrgica, com o auxílio do NSP, utilize a ferramenta 5W2H para a elaboração ainda mais 
específica do plano de ação de cada item, abrangendo nomes de servidores, datas, nível que o indicador deverá alcançar, entre outros pontos. A ferramenta $5 \mathrm{~W} 2 \mathrm{H}$ consiste em indicar para cada ação do plano de ação, quem será o responsável (who), quando será a data da tarefa (when), o que será feito (what), por que será feito (why), onde será feito (where), como será feito (how), quanto custará fazer (how much) ${ }^{(16)}$.

\section{Termo de Consentimento do Livre Esclarecido}

O paciente tem o direito de estar totalmente esclarecido em relação à cirurgia a qual ele será submetido, principalmente no tocante aos riscos e às possíveis complicações. Em suma, o médico fornece uma explicação detalhada a respeito da cirurgia a ser realizada e o paciente decide se ele quer ser operado ou não, caso ele queira, deverá assinar o termo de consentimento. É uma atribuição específica do médico e que possui obrigatoriedade legal. Além de ser importante para o paciente, também é importante para o hospital, pois é um respaldo jurídico.

Apesar de ser um procedimento fundamental, a frequência de não preenchimento é alta, como pode ser visto na figura 2 abaixo. Um total de 81,30\% dos checklists feitos possuem o item a respeito do termo de consentimento em branco. Ademais, ao lado de tal item, no próprio papel do checklist, existe outro chamado “consentimento não", o qual é marcado quando o coordenador confirma que não há presença do termo. O "consentimento não" foi marcado em 7,17\% dos feitos. As duas porcentagens somadas com a quantidade de checklists não preenchidos geram uma média de $90 \%$ de cirurgias sem que o termo de consentimento esteja assinado até o presente ponto de verificação.

Figura 1 - Histograma: Termo de Consentimento

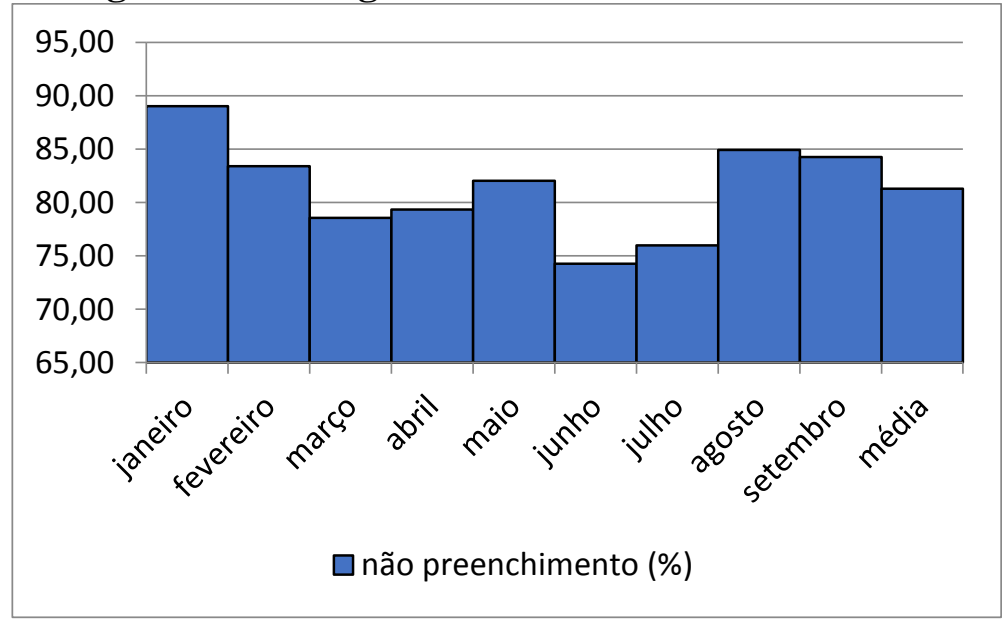

Fonte: elaborado pelos autores.

Segundo as entrevistas, atualmente, o momento fixado pelo hospital estudado para a assinatura o termo é na consulta em que o médico faz o pedido da cirurgia, porém, por meio dos dados apresentados, é possível notar que isso não vem acontecendo. Em tese, seria 
Revista Eletrônica Gestão \& Saúde ISSN: 1982 - 4785 Barbosa KR; Reis AS; Leitão FO e Gomes VC.

interessante que todo o esclarecimento fosse dado na consulta em que o médico pedisse a cirurgia e, em seguida, na consulta préoperatória, o paciente tirasse todas as dúvidas restantes e, ao fim, assinasse o termo. Sendo assim, ele teria tempo suficiente de refletir sobre a cirurgia juntamente com seus familiares. Contudo, o hospital estudado não tem condições de realizar a consulta préoperatória devido à escassez de profissionais.

Uma das entrevistadas afirmou que, apesar de o procedimento de assinatura do termo nunca ter sido efetivamente posto em prática, o uso do prontuário eletrônico teve influência negativa, principalmente em relação aos documentos que continuaram físicos. Todo o mobiliário para arquivar documentos foi descartado e uma quantidade considerável de secretárias das unidades foram demitidas. Mesmo que isso já tenha acontecido há cerca de dez anos, até hoje nunca se analisou as maneiras corretas de lidar com esses documentos, como é o caso do termo de consentimento.

Questionada sobre a possibilidade de inclusão do termo de consentimento em meio eletrônico, ela afirmou que o contrato com a empresa responsável pela implementação do sistema eletrônico já acabou. Dessa forma, não é possível inserir outras ferramentas no sistema por enquanto.
Gestão Da Qualidade Hospitalar: Estudo...

A organização estudada possui uma rotatividade considerável de profissionais, principalmente pelo fato de ser um hospitalescola. Segundo uma das enfermeiras, as instruções relacionadas ao item em questão não são ensinadas aos novatos, o que faz com que poucos deles saibam da necessidade de ter o Termo de Consentimento assinado e, consequentemente, muitos não colaboram para que o procedimento seja colocado em prática.

Além disso, o hospital possui clínicas de 11 especialidades e não há um termo de consentimento padrão que abranja todas elas. Em tese, cada especialidade tem o seu próprio. Contudo, na prática, muitas delas nem sequer possuem o termo feito. Como agravante, foi apontado que há períodos em que falta impressora e toner, o que impede a impressão dos termos.

Por fim, todas as entrevistadas afirmaram que a importância da assinatura do termo já foi enfatizada em reuniões com a alta direção. Todavia, em sequência, elas acrescentaram que nunca houve cobrança efetiva por parte dela. As causas apontadas pelas entrevistadas e as de interpretação das pesquisadoras foram representadas no diagrama de causa e efeito da figura 3 abaixo.

\section{Figura 3 - Diagrama de Causa e Efeito: Termo de Consentimento}




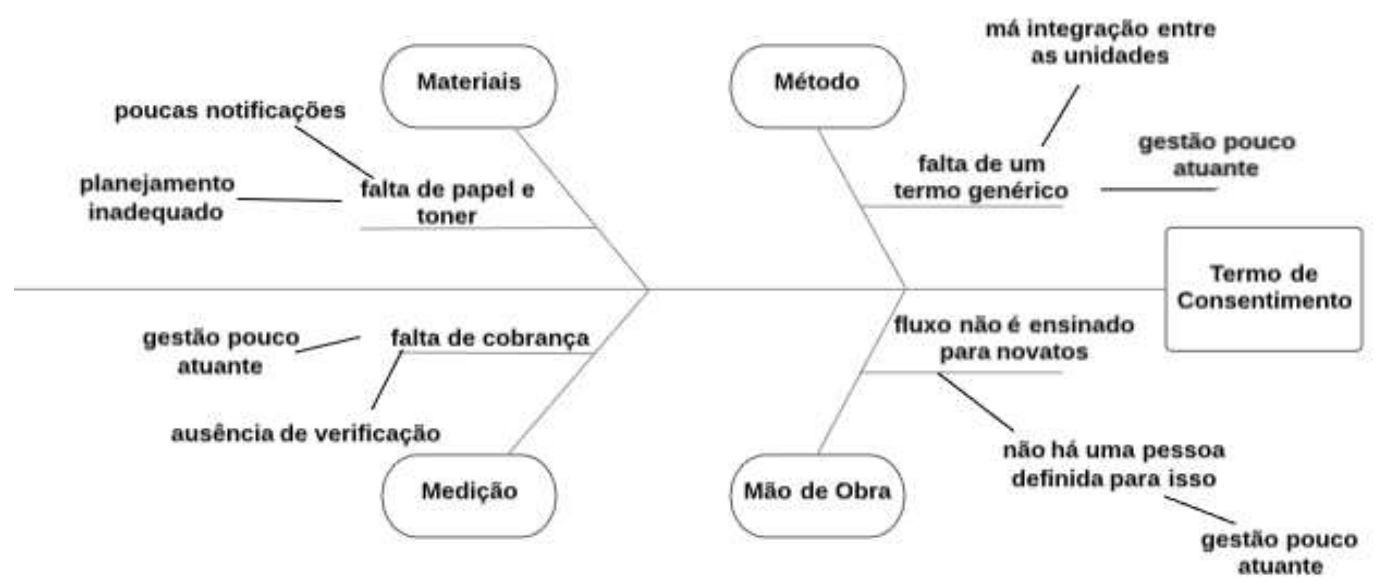

Fonte: elaborado pelos autores.

Como sugestões de curto prazo, temse a elaboração de um termo de consentimento genérico, ou seja, aplicável a todas as especialidades. Para um primeiro momento, seria interessante que o paciente assinasse o referido termo juntamente com a assinatura do termo de consentimento da anestesia, o qual é assinado na própria sala de cirurgia e que já virou rotina. Além disso, ele teria o tempo entre a consulta em que o pedido de cirurgia foi feito até o dia da operação para conversar com os seus familiares, visto que não há consulta préoperatória. Tal fluxo está representado na figura 4.

É necessário que a gestão do Centro Cirúrgico, juntamente com a alta gestão do hospital, decida quais procedimentos devem ser realizados em relação aos documentos que não foram recepcionados pelo sistema eletrônico. Por fim, a gestão do Centro Cirúrgico deve escolher pessoas chaves para acolher e passar as rotinas de trabalho para os novatos.

\section{Figura 2 - Fluxograma: Assinatura do Termo de Consentimento no curto prazo}




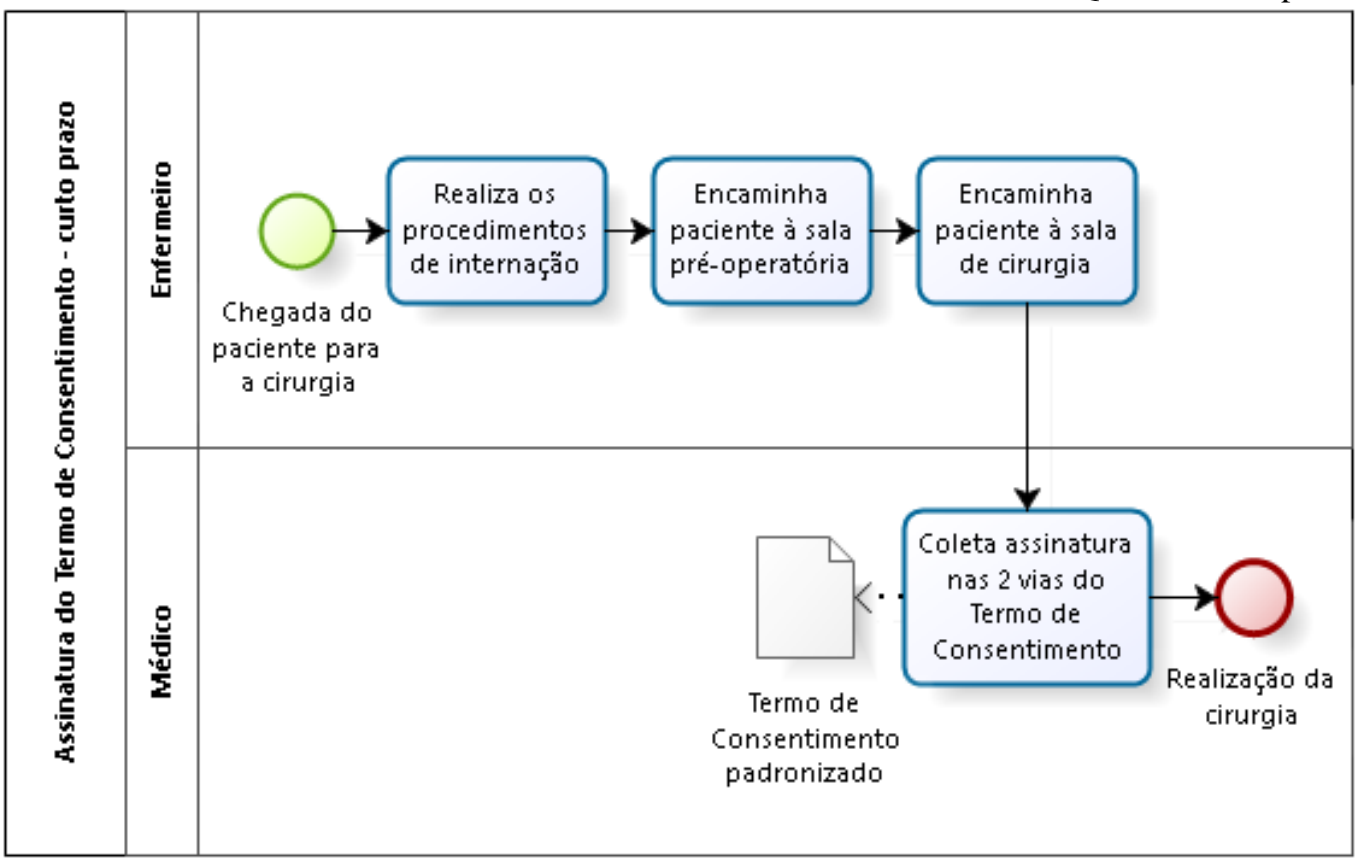

Fonte: elaborado pelos autores.

Em relação ao médio prazo, o fluxo mais próximo do ideal seria aproveitar o fluxo já existente em relação ao documento de solicitação de cirurgia. Na consulta em que o pedido de cirurgia é feito, o médico responsável já explicaria a cirurgia e tiraria as dúvidas do paciente. Nesse momento, duas vias do termo (já padronizado) seriam assinadas, uma ficaria com o paciente e a outra seria anexada ao pedido de cirurgia. Caso, posteriormente, o paciente mude de ideia em relação à cirurgia, ele teria a possibilidade de desmarcá-la.
Em seguida, o termo de consentimento e o pedido da cirurgia seriam encaminhados para a secretaria daquela clínica, que é a área responsável por marcar o dia da cirurgia e por enviar os documentos do paciente para o setor de admissão. É ao setor de admissão que o paciente se dirige quando chega ao hospital para ser internado no dia da cirurgia. Paciente e as devidas documentações são encaminhados para o andar da internação e, depois, para o centro cirúrgico. Tal fluxo foi representado na figura 5 . 
Figura 3 - Fluxograma: Assinatura do Termo de Consentimento no médio prazo

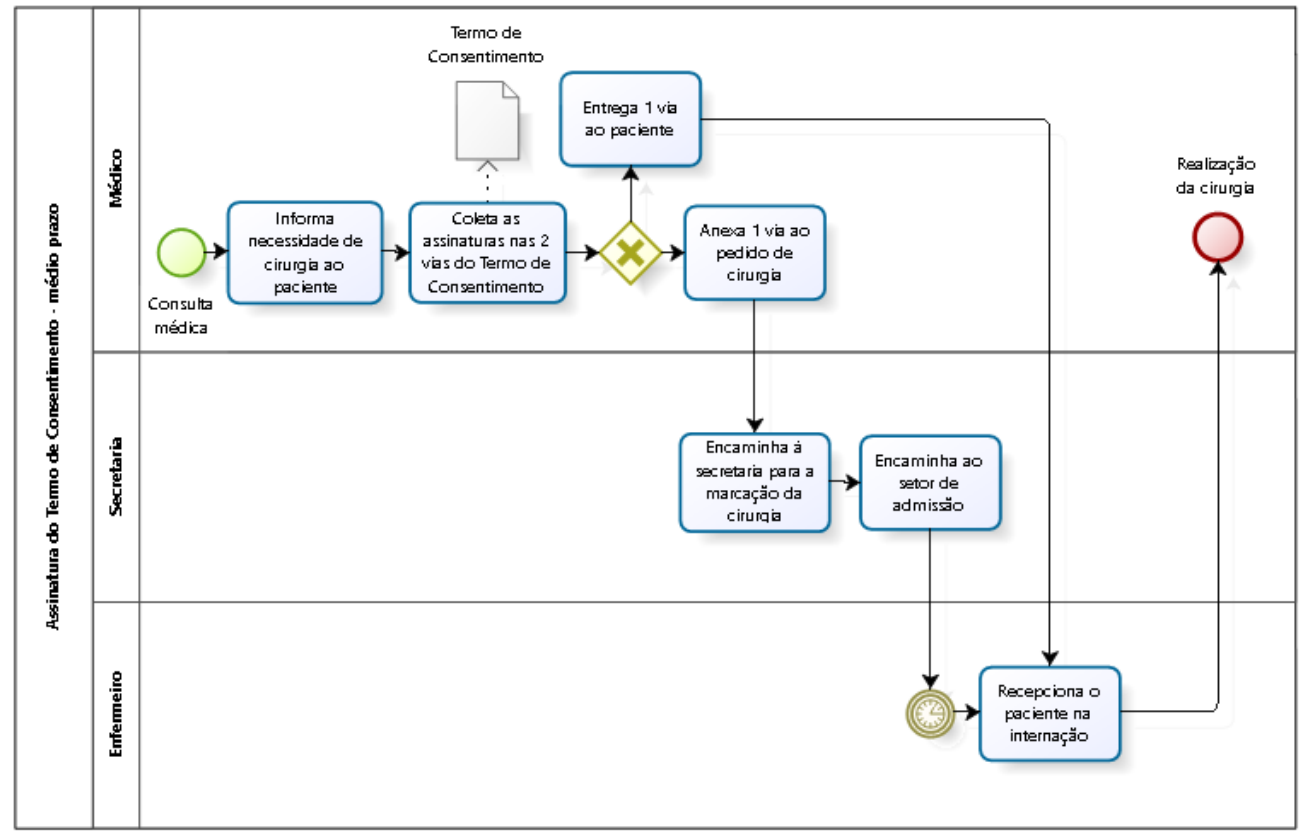

Fonte: elaborado pelos autores.

Já a longo prazo, por sua vez, o hospital deveria implementar a consulta précirúrgica e assinatura digital para pacientes. $\mathrm{O}$ termo seria assinado de forma digital, sem qualquer necessidade de papel, na própria consulta pré-operatória. Sendo assim, é necessário sensibilizar a alta gestão para a contração de mão de obra, bem como para a realização de um novo contrato para incluir o termo de consentimento no sistema eletrônico. Tal sensibilização pode ser feita por meio de reuniões periódicas e os resultados encontrados neste trabalho podem servir de base argumentativa. A alta gestão terá bastante tempo para preparar-se financeiramente, visto que são ações a serem concretizadas a longo prazo. Para futura análise de melhora de tal processo, o indicador sugerido é:

$$
\mathrm{I} 2=\frac{\text { Número de consultas pré-cirurgicas realizadas }}{\text { Total de checklists preenchidos }}
$$

\section{Marcação da lateralidade}

Segundo as entrevistadas, o corpo humano possui órgãos duplos e membros iguais, exemplos: pulmões e pernas, respectivamente. É necessário marcar a lateralidade quando o local a ser operado englobe algum dos dois grupos citados. Sendo assim, caso o paciente for operar a mão esquerda, ela deve receber uma marcação em formato de alvo para evitar que a direta seja operada por engano. Elas frisaram que marcar a lateralidade é uma atribuição própria do cirurgião. 
Por meio dessa atividade, consegue-se evitar que a cirurgia ocorra no órgão errado ou no membro errado. Tal falha geraria grandes prejuízos para a integridade física do paciente como também para o hospital. Apesar de sua notória importância, dos checklists preenchidos, 34,54\% estão em branco neste quesito. A evolução da frequência de marcação da lateralidade pode ser acompanhada no histograma feito (figura $6)$.
Segundo todas as profissionais, a maioria das cirurgias não requer que a lateralidade seja marcada, sendo assim, deveria ser marcado o campo "NA", ou seja, "não se aplica", fixado ao lado item relacionado à lateralidade. Contudo, uma delas afirmou que é possível que alguns circulantes não saibam o que significa tal sigla. Além disso, muitos circulantes sabem que o cirurgião simplesmente não marcou, por isso deixam em branco. Em suma, seria apenas uma questão de mau preenchimento.

Figura 6 - Histograma: Lateralidade

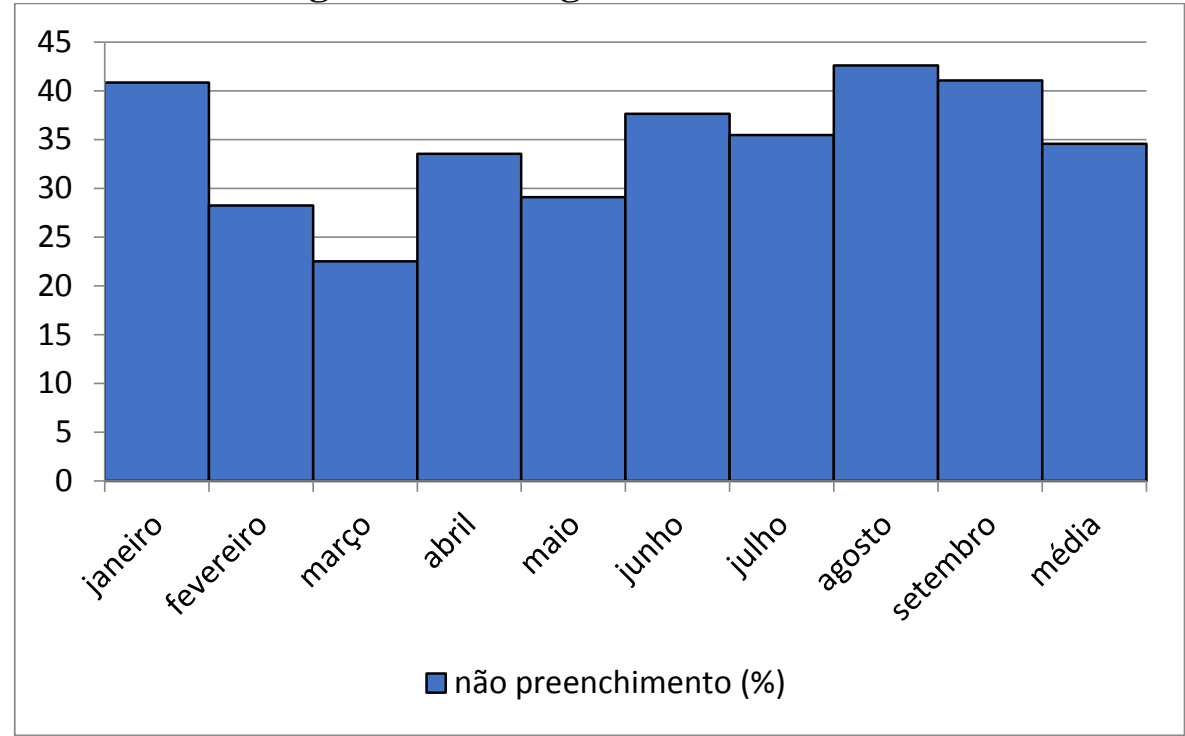

Fonte: elaborado pelos autores.

Além disso, elas notaram que falta conscientização por parte da equipe médica, que é responsável por fazer tal marcação. Uma das entrevistadas fez a seguinte afirmação: "a gente não consegue entender, mas muitos médicos se recusam a fazer (marcar a lateralidade)", ela também acrescentou que tal situação já foi passada para a direção, mas nenhum retorno foi dado. Outra causa apontada é o fato de não existir um momento pré-determinado para realizar a marcação: "falta estabelecer um fluxo para muitos pontos do checklist". Tais causas citadas e as de interpretação da pesquisadora estão descritas na figura 7. 
Figura 7 - Diagrama de Causa e Efeito: Marcação da Lateralidade

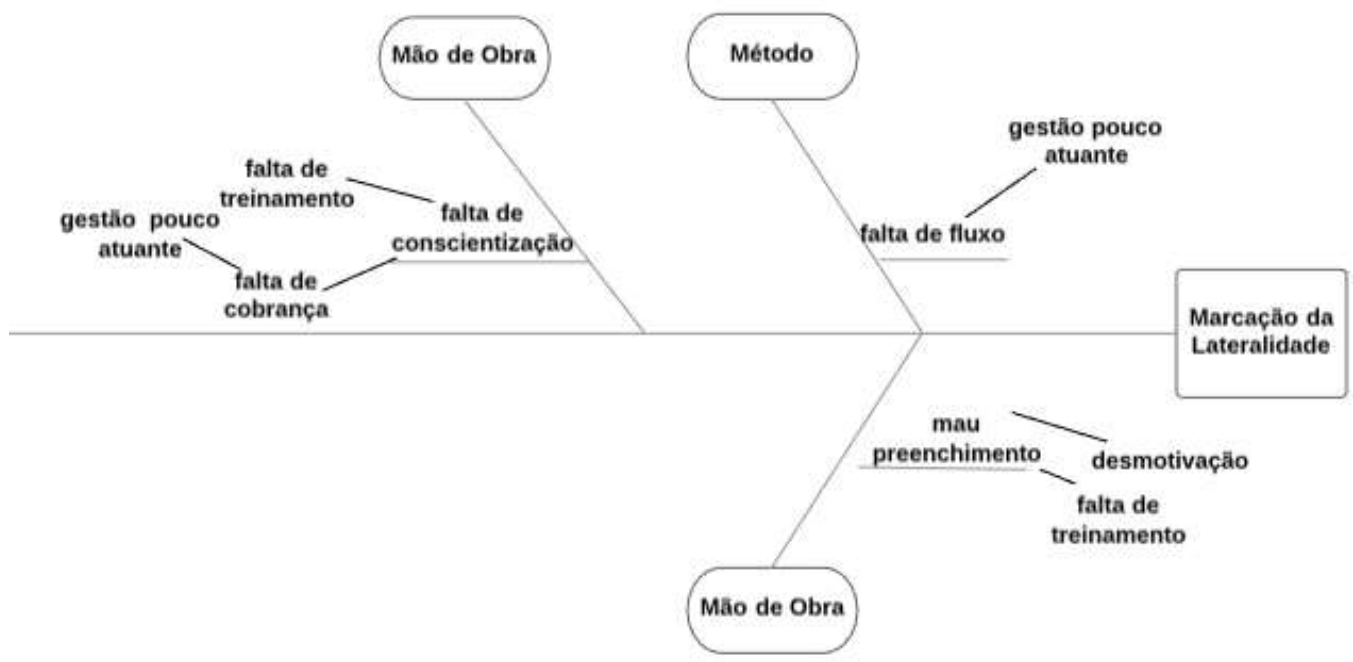

Fonte: elaborado pelos autores.

Uma solução em curto prazo, apontada pela a supervisora do centro cirúrgico, seria a de marcar a lateralidade na própria sala de cirurgia, antes da indução anestésica, ou seja, utilizar o momento destinado a conferir para marcar de fato. Para isso, é necessário realizar um trabalho de conscientização com os cirurgiões, visto que a responsabilidade pela marcação é dele e de que é uma forma de evitar erros que ele mesmo pode cometer.

Figura 8 - Fluxograma: Marcação de lateralidade no longo prazo

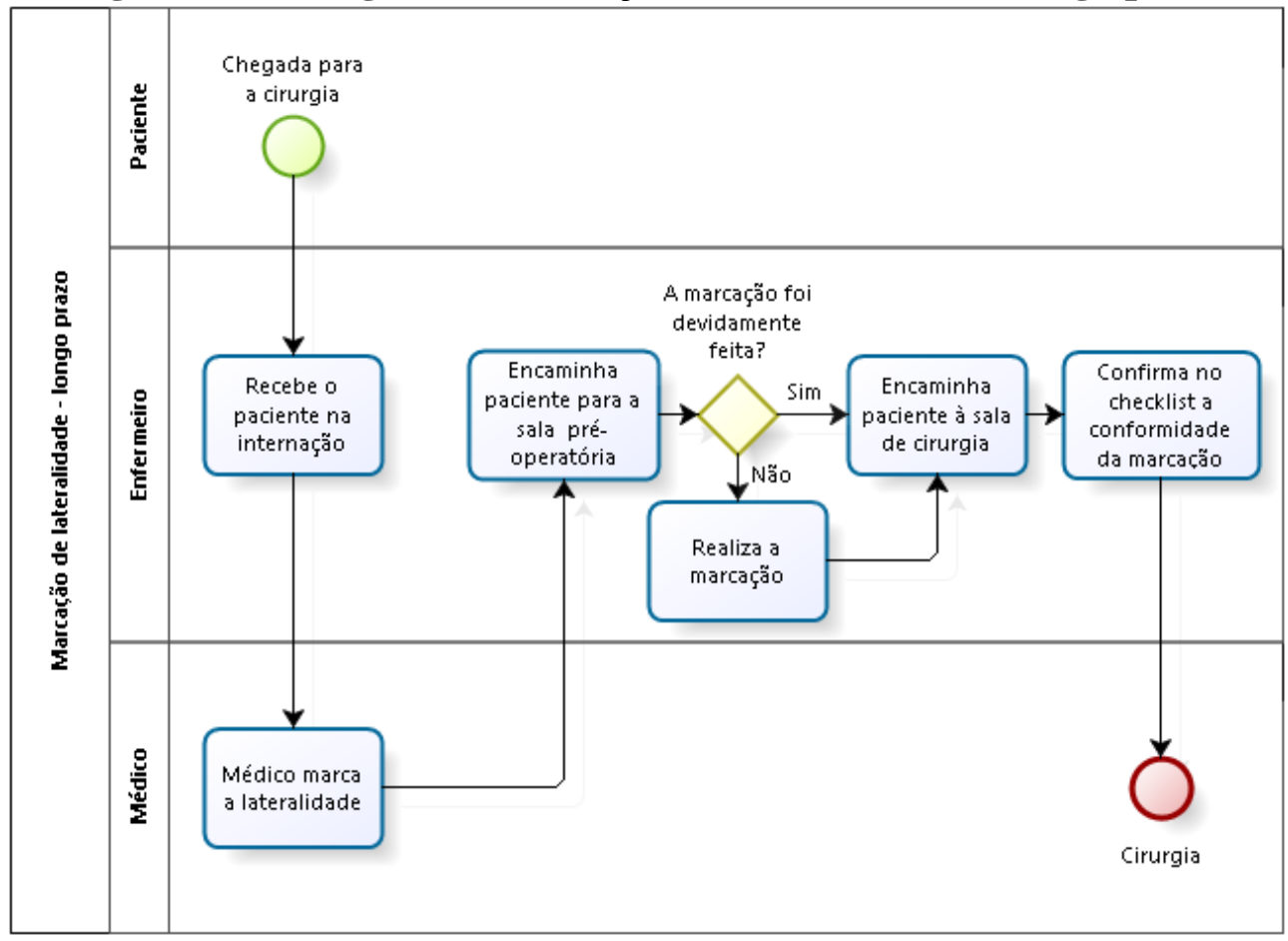

Fonte: elaborado pelos autores.

A longo prazo, seria ideal que o médico admitisse os seus pacientes na internação e já marcasse a lateralidade junto com o eles, na própria internação, pois, 
segundo uma das entrevistadas, é isso o que acontece em hospitais renomados do mundo todo. Em seguida, seria feita uma confirmação quando o paciente entrasse no centro cirúrgico (sala pré-operatória), caso, por algum motivo, não houvesse marcação, seria marcado nesse momento, por fim, outra checagem seria feita antes da indução anestésica, conforme orientação da OMS. Tal fluxo de processo é representado na figura 8 .

$\mathrm{O}$ indicador sugerido para $\mathrm{O}$ acompanhamento da evolução deste item é: cirurgias feitas no lado correto do paciente sobre a quantidade total de cirurgias realizadas.

$$
\mathrm{I} 3=\frac{\text { Cirurgias feitas do lado correto do paciente }}{\text { Total de cirurgias realizadas }}
$$

\section{Conferência do Marcador}

Segundo as entrevistadas, utilizar o marcador é de suma importância, pois, por meio do seu uso, pode-se evitar infecções no paciente. Uma delas definiu o marcador como sendo um "papelzinho dentro da bandeja dizendo que aquela bandeja foi esterilizada. Ele te dá a segurança de que aquela bandeja foi esterilizada". A bandeja é o recipiente em que ficam os instrumentais e

ao ser colocado nela, o marcador pode reagir mudando de cor, o que informa se o material está estéril ou não. Na análise feita dos checklists preenchidos, em 25,46\% dos casos as cirurgias foram feitas sem a confirmação da presença do marcador. Nota-se, pelo histograma feito (figura 9), que há meses com maior discrepância, como maio, junho e julho.

Figura 9 - Histograma: Conferência do Marcador

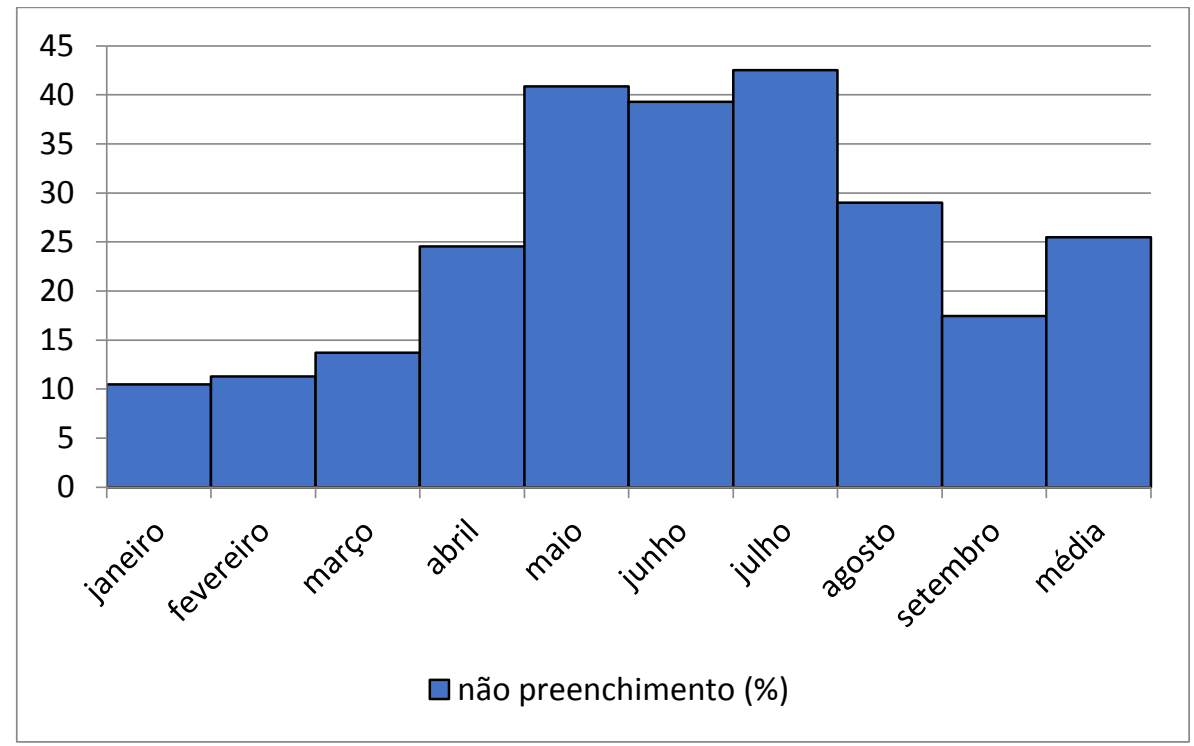

Fonte: elaborado pelos autores

A esterilização dos instrumentais é feita pelo próprio hospital no Centro de Material e Esterilização (CME), o qual é composto por enfermeiros e técnicos treinados na área. É interessante mencionar que sempre há um funcionário do Centro 
Cirúrgico escalado para resolver questões externas ao setor.

Já há um fluxo determinado para as atividades relacionadas ao marcador, o qual está representado na figura 10. Após a cirurgia, os instrumentais usados são levados pelo circulante para uma sala dentro do Centro Cirúrgico chamada de expurgo, em seguida, o funcionário escalado para resolver questões externas leva os instrumentais do expurgo para o CME para serem esterilizados, por fim, dias depois, a pessoa escalada para a área externa busca as bandejas e as guarda no estoque do Centro Cirúrgico. Antes da cirurgia, o circulante busca todos os materiais, inclusive a bandeja com o marcador e prepara toda a sala de operação.

Entre as causas apontadas para o não preenchimento do item está o fato de que há épocas em que falta o marcador, que, provavelmente são os meses de pico observados no histograma. Nesses casos, apenas uma bandeja de um ciclo inteiro vem com o marcador justamente para representar o ciclo todo. Segundo uma das entrevistadas, é obrigatório que todas as bandejas tenham o marcador.

Além disso, afirmou-se que a comunicação entre os membros da equipe tem sido ineficiente: o circulante deveria perguntar para o instrumentador ou o instrumentador deveria avisar para o circulante sobre o marcador. Algo que pode contribuir para tal situação é uma sobrecarga de trabalho do circulante: "o momento de início da cirurgia é muito rápido, ele precisa cuidar do paciente, preparar o material $e$ buscar itens que estão faltando, então pela correria a pessoa não pergunta".

\section{Figura 10 - Fluxograma: Esterilização de instrumentais}

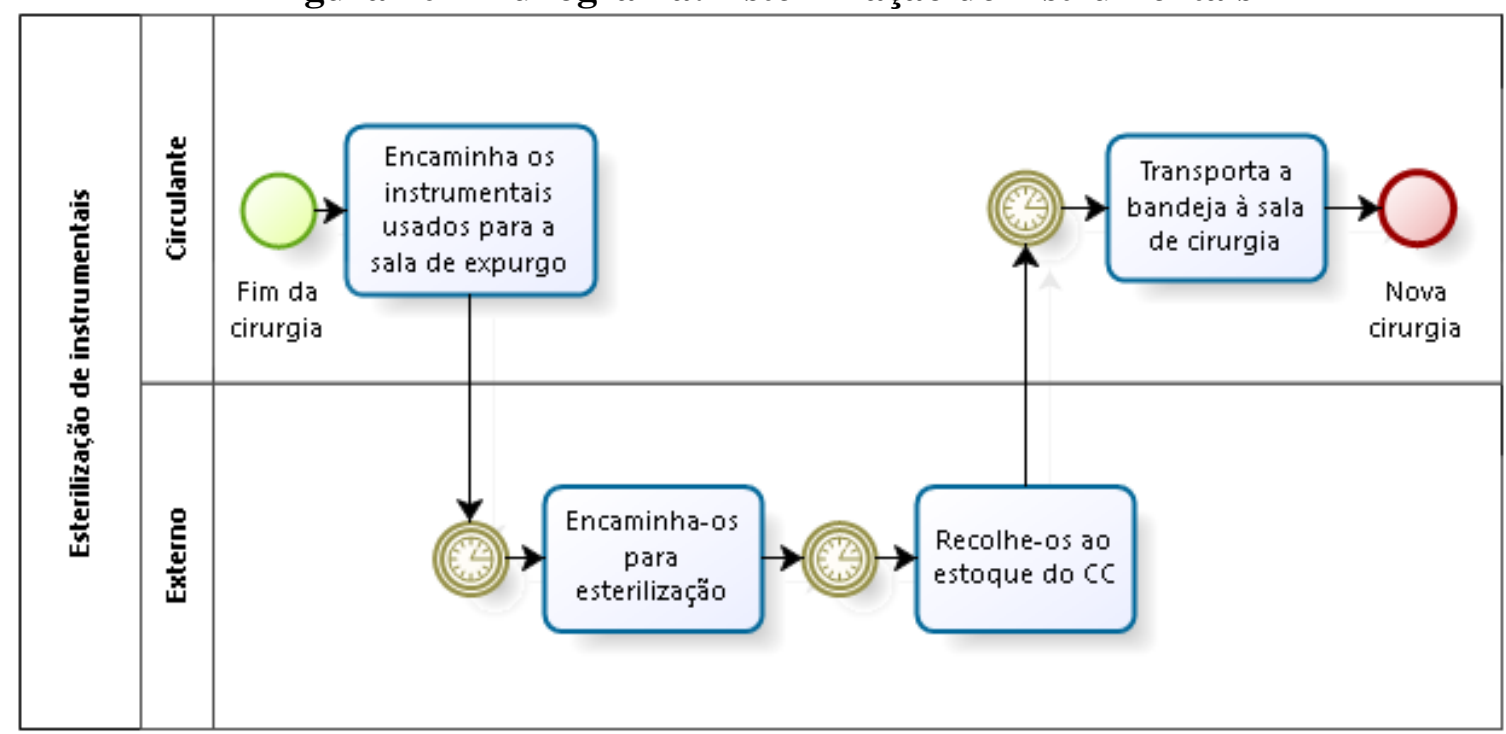

Fonte: elaborado pelos autores.

deixa em branco porque ele não foi lá ver se

Para uma das entrevistadas, o ponto crucial de tal problemática é a falta de comprometimento, ela acrescentou que "ele tinha" e "ele não quer marcar nem que sim nem que não porque ele não sabe". Por fim, foi apontado que "a rotatividade é grande e 
essas coisas (rotina) não são passadas para eles, então acaba que cada um faz do jeito que acha que é certo". Outra entrevistada afirmou que, de maneira geral, os funcionários mais recentes no centro cirúrgico são os que menos fazem os procedimentos relacionados ao checklist, ou seja, falta transmitir as rotinas para os novatos. As causas apontadas e as de interpretação da pesquisadora estão representadas no Diagrama de Causa e Efeito (figura 11).
Diante de tal contexto, uma estratégia para o curto prazo seria sensibilizar o instrumentador para que ele tome a iniciativa de avisar ao circulante sobre a presença ou não do marcador, isso poderia ser feito por meio de cursos e reuniões com a gestão do Centro Cirúrgico. Ademais, para chamar mais atenção para esse item, poderia ser criado um espaço no checklist só para a colocação do próprio marcador, visto que ele já vem com cola e que alguns funcionários já fazem isso.

\section{Figura 11- Diagrama de Causa e Efeito: Marcador}

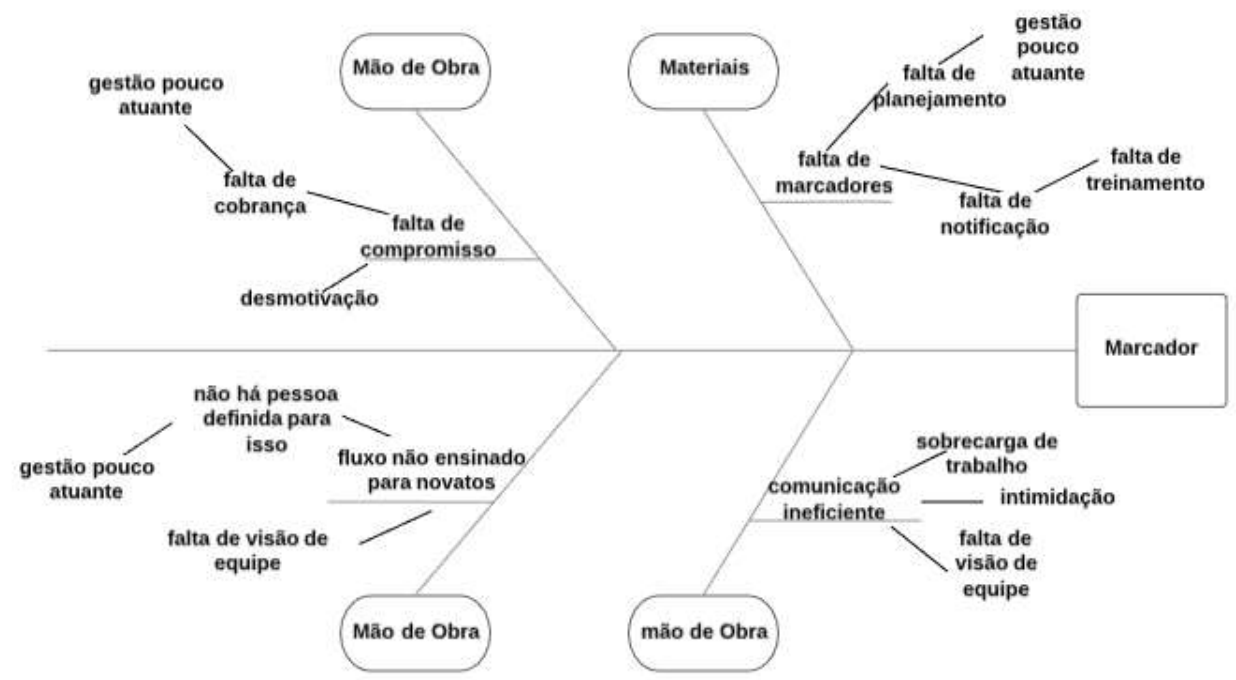

Fonte: elaborado pelos autores.

É necessário selecionar funcionários que já fazem o checklist adequadamente para serem responsáveis por passar os conhecimentos acerca da cirurgia segura para os novos servidores do setor. Além disso, trabalhar na comunicação da equipe, pois é necessário "envolver todo mundo que faz parte do processo". Por fim, é fundamental sensibilizar a alta gestão para que sejam garantidas as quantidades suficientes de marcadores. O indicador para futuras análises da evolução deste item é o de total de bandejas com marcador válido dividido pelo número total de cirurgias.

Número de bandejas utilizadas com marcador válido

$$
4=\text { Total de cirurgias realizadas }
$$

\section{Contagem de instrumentais}


De acordo com as entrevistadas, uma quantidade considerável de instrumentais pode ser utilizada ao longo de uma cirurgia e é possível que algum deles possa ser esquecido dentro de algum paciente. É interessante observar que apenas $o$ instrumentador pode tocar na mesa em que ficam os instrumentais e ele só entrega algum instrumento para o cirurgião depois que o cirurgião tiver devolvido o que estava sendo utilizado antes. Como pode ser observado na figura 12, dos checklists feitos, quase $20 \%$ possuem o ponto da confirmação da quantidade de instrumentais não preenchido.

Dentre as causas apontadas para o baixo número de preenchimento, está o baixo índice de esquecimento de instrumentais dentro de pacientes. Segundo as entrevistadas, é raro acontecer de instrumentais serem esquecidos dentro de pacientes porque os materiais são grandes. É mais comum que isso ocorra em cirurgias muito grandes, ou seja, quando todo o abdome é aberto. Além disso, é mais fácil que isso ocorra com compressas e gazes, porque elas são menores.

Figura 12 - Histograma: Conferência de Instrumentais

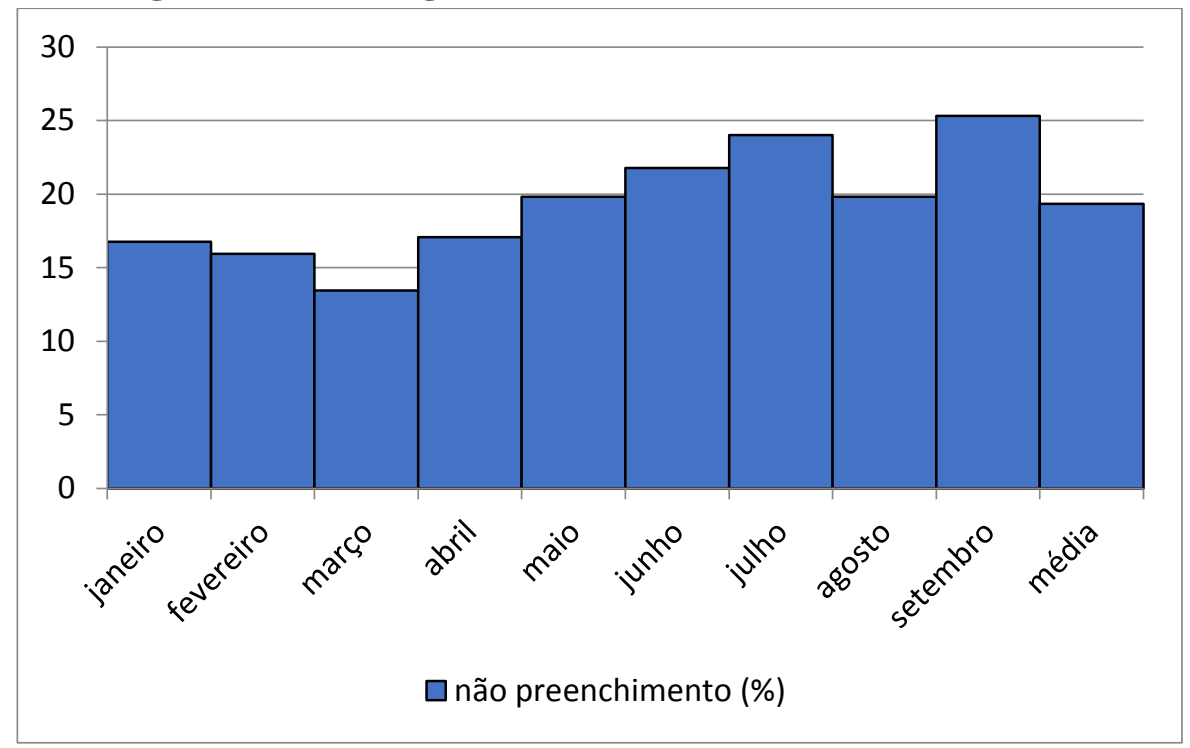

Fonte: elaborado pelos autores.

Outra causa apontada é que não há uma lista com os instrumentais presentes em cada bandeja: "não sabe exatamente o que vem (em cada bandeja), então não tem como conferir". Tal lista seria uma espécie de checklist para o instrumentador. Segundo uma das entrevistadas, todos os hospitais privados em que ela trabalhou possuem uma lista com o nome dos instrumentais presentes na bandeja. Contudo, é importante afirmar que o CME já está providenciando tal lista. Diante de todas as causas citadas e de interpretações feita pela pesquisadora, foi feito um Diagrama de Ishikawa (figura 13).

Uma solução seria conscientizar o instrumentador da importância da confirmação dele. Apesar de poucos casos, uma das enfermeiras afirmou que "há relatos 
Revista Eletrônica Gestão \& Saúde ISSN: 1982 - 4785

Barbosa KR; Reis AS; Leitão FO e Gomes VC.

nacionais e internacionais de esquecimento de instrumentais dentro de pacientes que geraram vítimas fatais". Tal medida poderia ser colocada em prática por meio de treinamentos e reuniões de conscientização com a gestão do Centro Cirúrgico.
Gestão Da Qualidade Hospitalar: Estudo...

A contagem de instrumentais poderá ser facilitada pela lista que está sendo preparada pelo CME. Contudo, será preciso outro trabalho de conscientização para colocála em prática, pois a sua existência não garante que a contagem será feita.

\section{Figura 13 - Diagrama de Causa e Efeito: Contagem de Instrumentais}

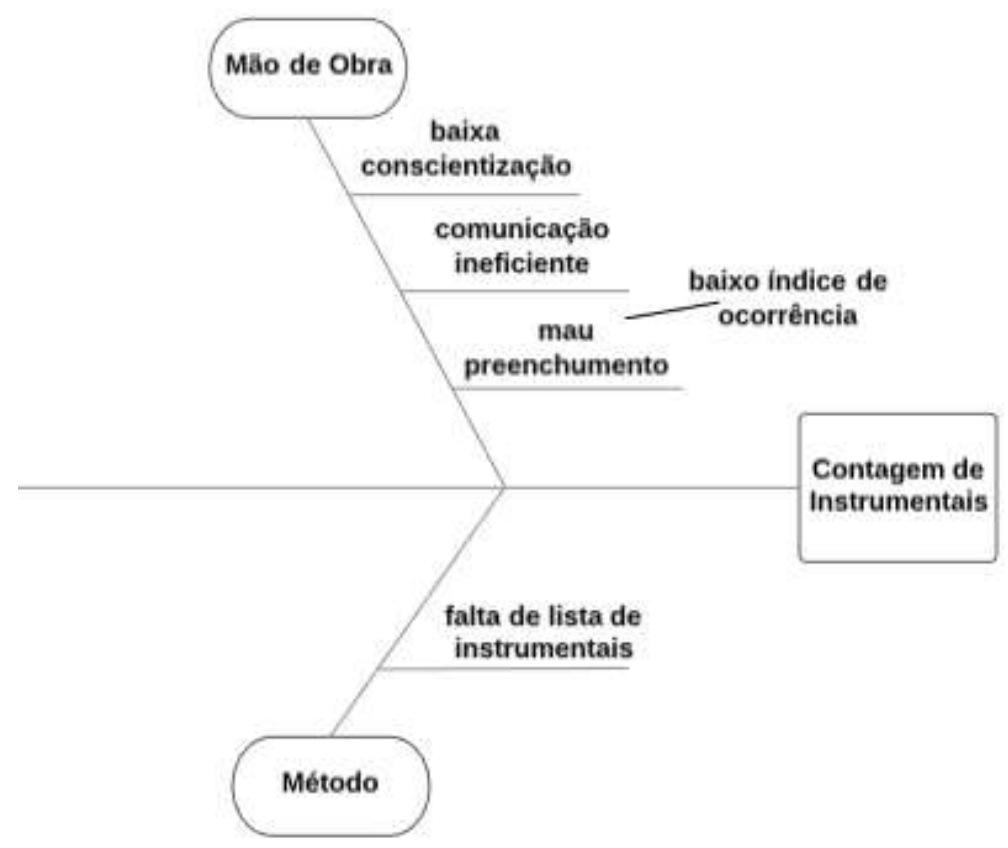

Fonte: elaborado pelos autores.

O indicador sugerido para acompanhar tal item é: quantidade de vezes em que o item da contagem de instrumentais está marcado pelo número total de cirurgias no mesmo período.

I5 $=\frac{\text { Quantidade de vezes em que o item da contagem de instrumentais está marcado }}{\text { Total de cirurgias }}$

\section{Análise da Observação Direta}

Oito cirurgias foram assistidas e nenhuma cumpriu as orientações dadas pelo manual do checklist da OMS. Por meio dele, sugere-se que todas as etapas sejam feitas em voz alta e com a participação da equipe. Contudo, o que ocorre, na prática, é que um bom tempo depois de iniciado o ato cirúrgico, o circulante preenche todo o checklist de uma só vez. Sendo assim, praticamente nada é conferido de fato. 
Corroborando tais observações, uma das entrevistadas fez uma série de afirmações importantes: "ele (circulante) senta lá, já rolou metade do checklist, aí ele senta $e$ preenche de maneira automática", "então aí perde a função, o objetivo, o propósito do checklist" e "aqui as pessoas se preocupam tanto com o papel e o que deveria ser realmente importante deixa de ser"

Uma das pesquisadoras presenciou um fato preocupante: ao final de uma histerectomia abdominal, na qual a paciente estava anestesiada apenas da cintura para baixo, o médico começou a colocar $\mathrm{o}$ micropore sobre os pontos para protegê-los. Contudo, a paciente viu e informou ao médico que ela era alérgica a micropore. Nesse sentido, caso a anestesia tivesse sido geral, ela não teria sido capaz de dar tal informação, o que poderia trazer complicações pósoperatórias.

Outro fato preocupante é a falta de ar condicionado em todo o Centro Cirúrgico, o que faz com que as salas cheguem a temperaturas muito altas. Uma das pesquisadoras presenciou uma operação em que o cirurgião precisou amarrar um pedaço de pano na cabeça para que o seu suor não caísse dentro do abdome aberto de um paciente. Além disso, a estrutura física do Centro Cirúrgico em si está bem danificada e há infiltrações em vários lugares.

\section{Conclusões e Recomendações}

A meta estabelecida no PSP do hospital estudado é a de aumentar a segurança na realização de procedimentos cirúrgicos. Para o auxílio no planejamento, três objetivos específicos foram definidos: avaliar o andamento da meta por meio da análise de checklists e de outros documentos, além de ter sido feita uma observação sistemática; identificar as causas do mau preenchimento dos checklists e de sua baixa adesão, o que foi feito por meio de entrevistas; e elaborar um plano de ação adaptado à realidade da organização.

No tocante ao primeiro objetivo, constatou-se que a taxa de adesão ao checklist ainda não está no patamar desejado. Em relação aos preenchidos, muitos possuem vários itens em branco ou que não são verdadeiramente checados. Por meio da observação sistemática, constatou-se que os checklists não são preenchidos da maneira correta, principalmente porque as pausas cirúrgicas não acontecem de fato. Dessa forma, ele virou apenas mais um documento a ser preenchido e não uma ferramenta capaz de auxiliar a equipe cirúrgica a evitar eventos adversos.

Em relação ao segundo objetivo, as causas apontadas para a não adesão e para a baixa qualidade do preenchimento dos checklists foram basicamente as mesmas. As principais são: baixo número de treinamentos, pouca conscientização, desmotivação, baixa participação dos gestores, comunicação deficitária entre a equipe cirúrgica, falta de 
insumos, estrutura física debilitada, entre outras. Por fim, quanto ao terceiro objetivo, os planos de ação foram traçados e tomaram como referência as causas de cada item do checklist selecionado pela análise de Pareto. Sugere-se que O Núcleo de Segurança do Paciente e o Centro Cirúrgico elaborem um 5W2H para um planejamento mais específico.

Diante do apresentado, todos os objetivos propostos foram alcançados. Entretanto, a presente pesquisa limitou-se a fazer uma análise apenas da organização estudada. Dessa maneira, os resultados encontrados e os planos de ação traçados não podem ser generalizados a outras organizações hospitalares, pois seus contextos podem ser diferentes. Por fim, outra limitação encontrada foi a falta de estudos e materiais referentes ao planejamento de metas em organizações hospitalares públicas, o que gera certa dificuldade em estabelecer parâmetros de comparação.

Sendo assim, esta pesquisa contribui com a academia no sentido de auxiliar na diminuição da defasagem de uma lacuna científica. Como medidas futuras, sugere-se que mais pesquisas sejam realizadas em diferentes organizações hospitalares, sendo aprofundadas, além do alcance de metas, questões de motivação, conscientização, trabalho em equipe e relacionamento com a alta gestão. Além disso, pode-se elaborar outra pesquisa que utilize mais aspectos da administração da produção no sentido de detecção ou prevenção de falhas, como o FMEA ou árvore de falhas.

Ainda que em escala menor, foi possível observar que há profissionais realmente comprometidos com a questão da segurança do paciente cirúrgico. Sendo assim, pode-se considerar que avanços já foram feitos. Contudo, há ainda muito a ser feito no sentido de conscientizar organizações e profissionais a respeito da importância do cuidado seguro. 


\section{Referências}

1. Grazziano ES, Viana DL, Harada MJCS, Luz MGP. Enfermagem perioperatória e cirurgia segura. São Paulo: Yendis; 2016.

2. Agência Nacional de Vigilância Sanitária (Brasil). Resolução no ${ }^{\circ} .36$, de 25 de julho de 2013. Institui ações para a segurança do paciente em serviços de saúde e dá outras providências [portaria na internet]. Diário Oficial da União 26 jul 2013 [acesso em 18 set 2018]. Disponível em:

http://portal.anvisa.gov.br/documents1 $\underline{\text { 0181/2871504/RDC_36_2013_COMP }}$ .pdf/36d809a4-e5ed-4835-a3753b3e93d74d5e

3. Nascimento AB. Gestão hospitalar e qualidade do atendimento. São Paulo: Pearson Education do Brasil; 2017.

4. Luongo J. Gestão da qualidade em saúde. São Paulo: Rideel; 2011.

5. Wachter RM. Compreendendo a segurança do paciente. 2. ed. AMGH: Porto Alegre; 2013.

6. Gonzalo VN, Malik AM. Gestão em saúde. 2. ed. Guanabara Koogan: Rio de Janeiro; 2018.

7. Brasil. Ministério da Saúde. Gabinete do Ministro. Portaria $n^{\circ} .529$, de $1^{\circ}$ de abril de 2013. Institui o Programa Nacional de Segurança do Paciente (PNSP) [portaria na internet]. Diário Oficial da União 02 abr 2013 [acesso em 17 set 2018]. Disponível em http://www.saude.mt.gov.br/upload/co ntrole-infeccoes/pasta2/portaria msgm-n-529-de-01-04-2013.pdf

8. Brasil. Ministério da Saúde, Fundação Oswaldo Cruz, Agência Nacional de Vigilância Sanitária. Documento de referência para o Programa Nacional de Segurança do Paciente [Internet]. Brasília: Ministério da Saúde; 2014 [acesso em 18 set 2018]. Disponível em:

http://bvsms.saude.gov.br/bvs/publica coes/documento_referencia_program nacional_seguranca.pdf

9. Mendes W, Moura, MLO. Avaliação de eventos adversos cirúrgicos em hospitais do Rio de Janeiro. Rev Bras Epidemiol [periódicos em Internet]. 2012 set [acesso em 18 set 2018]; 15(3). Disponível em: http://www.scielo.br/pdf/rbepid/v15n/ 07.pdf

10. World Health Organization (WHO). WHO Guidelines for safe surgery 2009. Safe surgery saves lives [Internet]. Genebra: WHO; 2009 [acesso em 18 set 2018]. Disponível em:

http://www.who.int/patientsafety/safe urgery/en/

11. Ferraz EM. A cirurgia segura: uma exigência do século XXI. Rev Col Bras Cir [periódicos na Internet]. 2009 jul [acesso em 18 de setembro de 2018]; 36(4). Disponível em: http://www.scielo.br/pdf/rcbc/v36n4/a 01v36n4.pdf

12. Yin RK. Estudo de caso: planejamento e métodos. 5. ed. Porto Alegre: Bookman; 2015.

13. Gil AC. Como elaborar projetos de pesquisa. 6. ed. São Paulo: Atlas; 2017.

14. Silva EL, Menezes EM. Metodologia da pesquisa e elaboração de dissertação. 4. ed. UFSC: Florianópolis; 2005.

15. Nogueira LCL. Gerenciando pela Qualidade Total na Saúde. 2. ed. Belo Horizonte: Editora de Desenvolvimento Gerencial; 1999.

16. Martins PG, Laugeni FP. Administração da Produção. São Paulo: Saraiva; 2005. 


\section{Participação dos autores:}

Barbosa KR trabalhou na concepção teórica, coleta de dados, análise estatística e elaboração e redação final do texto;

Reis SA trabalhou na concepção teórica, coleta de dados e análise estatística;

Leitão FO trabalhou na revisão final do texto;

Gomes VC trabalhou na revisão final do texto;

Recebido: 30.07.2019

Revisado: 26.08.2019

Aprovado: 03.09.2019 